\title{
50 años y 50 números, un itinerario de coincidencias y búsquedas
}

\author{
Antonio Elizalde \\ Fundador de POLIS, Revista Latinoamericana, Santiago, Chile. \\ Email: antonio.elizalde@gmail.com
}

50 años, medio siglo, son un tiempo suficiente para poder evaluar logros y fracasos de procesos históricos e institucionales. De manera similar, los 50 números de una revista muestran ya una existencia consolidada en la tarea de publicar artículos de muchos autores, más aún cuando se trata de una revista científica en la cual se difunde parte importante de la producción intelectual de esta parte del mundo, de modo que es posible hacer un inventario de lo perseguido y de lo logrado.

Esta coincidencia entre el aniversario 50 de nuestra revista con los 50 años transcurridos desde los sucesos de mayo del 68 en París, que marcaron un hito en la conciencia colectiva de la humanidad, pero que al igual que otros sucesos parecidos nuestra historia común, fueron precedidos, coetáneos y antecedentes para numerosos otros procesos de índole similar, como la Primaverade Praga del cual da cuenta la novela de Kundera "La insoportable levedad del ser", o la matanza en la Plaza de las Tres Culturas de Tlatelolco en Ciudad de México en 1968 y que recién hoy 50 años después se logra finalmente, gracias a la elección de AMLO, alcanzar los objetivos perseguidos por esa generación masacrada allí; la toma de la Casa Central de la UC el año 1967 que dio origen a la reforma no solo en esa universidad sino que en el conjunto de las universidades chilenas de la época; las protestas de la Plaza de Tiananmen en 1976 que llevaron a la expulsión de la Banda de los Cuatro y la masacre ocurrida en esa misma plaza 13 años después en 1989. Hechos todos estos que expresaron en el siglo recién pasado y que continúan haciéndolo manifiesto hoy, el afán libertario propio del espíritu humano y la persistente lucha por avanzar hacia las promesas incumplidas de la Modernidad: Libertad, Igualdad y Fraternidad.

En una sociedad, como la chilena, recién salida de una largo período dictatorial, que nos había dejado como herencia muchos aspectos negativos como: pobreza, desigualdades, corrupción, marginación, discriminación, autoritarismo, intolerancia, fundamentalismos, nacionalismos agresivos y otros; pero que además enfrentaba, así como el resto de la humanidad, por una parte los desafíos surgidos de la enorme aceleración del tiempo histórico debido al exponencial crecimiento del acervo científico y tecnológico; y por la otra, de un cambio sin precedentes en la historia humana en estilos y formas de vida con el surgimiento del hiperconsumo y del turboconsumidor, la transformación del ciudadano en cliente y de la política 
en espectáculo, de la realidad en virtualidad, de la verdad en producto manipulable, y de la naturaleza, la vida y la propia dignidad humana transformadas en mercancías. Enfrentados a ello, la revista Polis ambiciosamente quería hacer manifiesta esta complejidad y aportar en búsquedas para dar cuenta de ella.

“De una parte, publicaremos ensayos de carácter crítico, en los que se expresan las limitaciones de los discursos, y de las realidades sociales y culturales; de otra parte, nos interesa dar espacio al pensamiento alternativo, a la búsqueda de nuevos paradigmas, de nuevas propuestas de pensar, de investigación, de nuevos saberes inter y multidisciplinarios, a nuevos procesos de formación de conocimientos, de aprendizajes que incorporen la experiencia directa y los conocimientos espontáneamente constituidos, en los cuales las conceptualizaciones se articulen y enriquezcan en una relación sinérgica con las prácticas.”

Es así como ya desde su primer número buscó abrir espacio a una reflexión crítica y provocativa en torno a temas sobre los cuales no se hablaba aún mucho en el ámbito académico. Su propia estructura interna marcó una diferencia respecto a otras revistas universitarias. La primera sección de la revista, “Lente de aproximación”, como su nombre lo sugería tenía y tiene un carácter monográfico, buscando profundizar un determinado tema al cual se convocaba en cada número.La segunda sección fue denominada “Cartografías para el futuro”. Como su nombre lo indicaba estaba dedicaba a presentar textos exploratorios que apuntasen a generar nuevas formas de saber. La tercera parte de la revista llamada “Propuestas y avances de investigación” estuvo dedicada a recibir aportes de investigadores respecto a estudios que se estaban efectuando en el ámbito universitario. La cuarta sección de la revista "Bosquejo de una nueva episteme” fue diseñada para proveer trabajos que permitiesen abrirse a otras maneras de concebir la realidad y otras formas de aproximarse a ella, buscando nuevos modos de producción de verdad, esto es de coherencia entre las afirmaciones que se hacen respecto a estados del mundo y dichos estados.

Nos impulsaba la convicción que la episteme predominante propia de Occidente es incapaz de aceptar la existencia de otras "verdades" contradictorias o cuestionadoras de sus propias certidumbres, tanto por su etnocentrismo cultural, así como por su acendrada tendencia a concebir la realidad de modo dualista. De este modo, se tiende a interpretar la realidad y a sí mismo en términos, conceptos o interpretaciones opuestos, de las cuales se supone que uno debe ser verdadero y las otros falsos, no existiendo espacio para pensar aquello que no quede incluido en esas categorías mutuamente excluyentes. Por ello es que resulta muy difícil pensar nuevas posturas o concepciones que superen o integren los opuestos. Interrogarnos permanentemente respecto a la validez de este pensar dualista -proveniente tanto de la filosofía platónica como de la tradición judeocristiana- es el propósito deliberado con que seleccionamos estos "bosquejos". 
Con esta estructuración interna la revista operó durante más de una década, período durante el cual fue progresivamente fue alcanzando un reconocimiento que le permitió ser incluida en varios repositorios virtuales de carácter internacional, y comenzar a ser indizada. Pero las mismas demandas surgidas desde espacios de reconocimiento académico obligaron a ir modificando su estructuración y carácter. Cumplió, sin embargo, su tarea de introducir en el ámbito de la investigación y reflexión teórica, temáticas y dimensiones de la realidad, relativamente marginadas y ausentes en el trabajo de la academia.

Es así como la revista en su primer número abordó la temática universitaria, realidad de la cual formaba parte. La institución universitaria, la única que se conserva del mundo medieval y colonial, concebida idealmente como comunidad de profesores y estudiantes,y que requiere, sin duda, de una profunda revisión y actualización, que compare y evalúe su realidad actual con su concepto.

El segundo número abordó el tema de la desolación, aislamiento y soledad, producida en una sociedad en la cual se destruyó gran parte de sus organizaciones y se instaló un imaginario individualista extremo y la necesidad y surgimiento de nuevos vínculos sociales.

En su tercer número se propuso la mirada desde el descentramiento, desdelugares y espacios que no son los habituales, que se sitúan en los márgenes. Se presentan fragmentos de visiones de los excluidos, de los marginados y "condenados de la tierra”, así como pensamientos y formas de acción rebeldes que rechazan toda forma de coerción social. Otros están escritos desde la "anormalidad"; desde los estigmatizados por su condición física o el carácter de su labor. Se hacen presentes notables historias de olvidadas luchas sociales del pasado, temas relegados u omitidos en la sociedad chilena. Nos asistía la convicción que en nuestra cultura occidental, la mirada tiende a organizarse con un eje central, expresado metafóricamente en lo que podríamos llamar las medidas de tendencia central: la mediana, el promedio, la moda. En la visión positivista predominante, la norma estadística suele transformarse en norma moral, norma jurídica, norma científica. En importante medida, el llamado esfuerzo civilizatorio, en sus distintas versiones, incluida la modernización neoliberal, es un esfuerzo normalizador, estandarizante; un conjunto de estrategias discursivas de exclusión de grupos, de fenómenos, de conflictos y contradicciones. Un esfuerzo permanente de simplificación, de reducción de las disonancias que cuestionan las semi-certezas y de reproducción del pensamiento único, y de lo "políticamente correcto".

El cuarto número se preguntó si ¿Es posible otra globalización? confrontando miradas provenientes desde el Norte y el Sur.La idea de "globalización” contiene una carga semántica absolutamente disímil para las personas dependiendo de donde estén ubicados, sea en el norte o en el sur de nuestro planeta, o en el norte o sur de nuestros países. Según algunos autores, implicapara la mayoría dimensiones perversas y destructivas, 
mientras que otros piensan en las posibilidades que abre. Surgen así diversas interpretaciones, algunas de las cuales hemos querido mostrar en este número, buscando responder a preguntas como: ¿existe una “errónea” identificación de la globalización con el neoliberalismo? ¿Son fenómenos separables? ¿Es posible otra globalización? ¿Qué se requiere para ello? ¿Cuál globalización es compatible con la sustentabilidad, con la inclusión social y con la vida buena?, ¿qué novedad histórica representa la globalización?

El quinto número se tituló Sustentabilidad: ¿para todos o sólo para algunos? y abordó la absoluta asimetría existente en la distribución de los costos ambientales del crecimiento económico en sus modalidades históricas y actuales. Pues el desarrollo de unos pocos es absolutamente insustentable salvo transfiriendo hacia terceros los costos o externalidades de su propio estilo de desarrollo. Estados Unidos debería internalizar los costos de un modelo tremendamente derrochador de energía y al hacer así haría así aún mucho menos competitiva su economía de lo que actualmente es a nivel global. Los conflictos del Medio Oriente se explican por la búsqueda del control de la principal fuente energética del hegemónico modelo productivo existente hoy en los países del Primer Mundo. Un mundo sin petróleo tornaría de la noche a la mañana en absolutamente ineficientes a las actuales economías “desarrolladas”. De allí que la noción de sustentabilidad ha permitido introducir un criterio para juzgar las instituciones y las prácticas vigentes en las llamadas sociedades modernas. Al igual que muchos otros conceptos en la historia de las ideas, hay una cierta parte de novedad intrínseca al concepto, que al ser tal ya comienza a cuestionar ideas previas y a abrir paso a otras concepciones distintas de las dominantes. Nos alimenta la profunda convicción de que es imprescindible transitar hacia una nueva cosmovisión que substituya la aún vigente. La idea de sustentabilidad nos está ayudando a diseñar y dibujar una nueva visión, una nueva comprensión, una nueva cosmología, urgente y necesaria para enfrentar los enormes desafíos que enfrentamos. Porque el cambio fundamental de realizar no está tanto en el plano de la tecnología, ni de la política o de la economía, sino que está radicado principalmente en el plano de nuestras creencias, ya que son ellas las que determinarán el mundo que habitemos.

El número 6 de Polis se orientó hacia un rescate de las utopías y sueños colectivos. El imaginario que se ha ido instalando en el mundo que vivimos, ha desechado lo que ha sido un elemento constitutivo hasta ahora en la historia de la humanidad: la capacidad de soñar con un mundo distinto y mejor al que hemos sido capaces hasta ahora de construir. Hemos pasado abruptamente desde una época casi delirantemente utópica, al descrédito y desplome casi absoluto de todas las utopías. El desplome de los intentos por plasmar históricamente la construcción utópica de un mundo sin explotación, desarrollada en el marco de los socialismos reales, implicó para gran parte de la intelectualidad progresista el derrumbe de sus apuestas históricas, pero también un notorio detrimento de la influencia del ideario progresista en la arena política, y una desorientación y pérdida de rumbo de gran parte, por no decir de todas, las organizaciones políticas cuyo sentido his- 
tórico ha sido constituirse en la expresión de los intereses populares y de los sectores sociales menos privilegiados. El carácter de lo utópico, como elemento imprescindible para la existencia humana es algo que actualmente se tiende a desconocer. La utopía en cuanto tensión escatológica, es decir, como aquello que no está en el presente pero que podría estar en el futuro, ha acompañado al acaecer humano desde los orígenes de la historia. Es posible sostener que la historia requiere de una escatología, y por tanto de utopías. ¿Qué sería de la existencia sin referentes futuros, deseables, soñables y potencialmente vivibles? ¿Sería posible vivir sin sueños de algo mejor? La condición humana nos provee de algo único entre los seres vivos, cual es nuestra capacidad de imaginar escenarios distintos a la realidad que vivimos, saliéndonos o desbordando los límites que nos pone la realidad. Es por eso que creemos que frente a la presente desvalorización de las utopías, es necesario iniciar un esfuerzo de recuperación de la capacidad de utopizar, con la prevención de no olvidar el necesario carácter radicalmente inconforme del referente utópico, que nos permita mantenernos en alerta permanente frente a las tentaciones propias del ejercicio de todo poder. Hay aquí una profunda relación -ambigua pero inevitable- entre política y ética, que es imprescindible abordar y ahondar en su reflexión. Pensamos asimismo, hoy, a diferencia de lo que se creyó ingenuamente en el pasado reciente, que no es posible realizar un sueño único, que sea capaz de metabolizar y subsumir todas las demandas por justicia e igualdad reivindicadas por los diversos explotados del mundo. La utopía subsiste, pero se halla dispersa; no atomizada, ni fragmentada, sino distribuida de manera válida y legítima en muchos sueños individuales y colectivos. Creemos que hoy es posible la utopía de la diversidad, del valor legítimo y cierto -en cuanto vivencia humana- de todos los sueños por un mundo mejor.

El séptimo número tuvo como tema central la(s) ciencia(s), la(s) tecnología(s) y la producción colectiva de saber(es). El desarrollo científico en nuestros países, llegados tardíamente a la revolución industrial, de frustrada y asimétrica industrialización, es claramente insuficiente y aún no han logrado incorporarse a la nueva revolución científico-tecnológica. Simultáneamente, nuestras sociedades se encuentran en un proceso de profundas transformaciones en su sistema institucional y en su cultura. Se ha producido un déficit de conocimiento social, entendido como autorreflexión social y no sólo como producción de información empírica directamente aplicable. Esta situación se genera en el contexto de una nueva crisis de modernidad o bien, piensan otros, de un cambio civilizatorio en nuestras sociedades. No sabemos bien cuál será el papel de las ciencias naturales y sociales en esta nueva configuración, y su relación con la reafirmación, surgimiento y desarrollo de los saberes populares, de las culturas autóctonas, juveniles, de género y espirituales generados colectiva o espontáneamente. Asimismo se necesita reflexionar sobre el vínculo entre las ciencias y el desarrollo democrático de nuestros países por los elementos vinculantes entre ciencia, tecnología, cultura y convivencia social.

El octavo número se planteó un tema absolutamente ausente en la reflexión académica, se tituló Espiritualidad y el cambio social: ¿̨realidades 
antinómicas? y se propuso confrontar la aparente antinomia que durante varias décadas del siglo pasado empujó a muchas personas a tener que optar entre el cambio personal y el cambio social, a partir de nuestra intuición o convicción que ella se ha ido disolviendo en las décadas recientes. En el pasado, esta disociación llevó a que muchas personas acogieran la perspectiva de la espiritualidad como una ideología o falsa conciencia - "la religión como el opio del pueblo”-, y que incluso fuera considerada como un obstáculopara el cambio y la transformación social. Hoy se puede reconocercómoun gran número de individuos comprometidos con el cambio social a su vez tienen clara conciencia de la necesidad de que éste se encuentre anclado en un profundo cambio personal. Nos quisimos preguntar también qué diálogos se pueden establecer en este territorio de la multiculturalidad actual, entre -por un lado- los mega relatos que alimentaron la ideología del progreso durante casi más de dos siglos, a partir del surgimiento de la ciencia moderna y del fenómeno de la Ilustración -y que desplazaron el monopolio del rol moralizador cumplido por las distintas religiones al sustentar los valores no ya en el mandato heterónomo y la obediencia a las normas provistas por un ser superior, sino el producto de la voluntad del sujeto expresada en un contrato social al cual se liga desde el ejercicio propio de su autonomía-, y por otro lado el surgimiento de nuevos tipos de espiritualidad con características "laicas”, “agnósticas”, "híbridas" o "sincréticas”, entre otras denominaciones posibles, y que integran en su visión de mundo dimensiones referidas a la vida en común y al bien de la comunidad.

En el número 9 se trató el tema Género y Sustentabilidad en el cambio civilizatorio.Las condiciones sociales y de desarrollo de la sociedad moderna determinan la invisibilidad de la naturaleza y de la mujer, fundamentalmente, en este segundo caso, en lo que respecta al trabajo femenino no asalariado, a las actividades de reproducción y cuidado de la vida. Ello se produce, seguramente, porque las prestaciones que una y otras ofrecen no producen unas plusvalías inmediatas y se concretan, en gran parte, en bienes intangibles y valores que no cotizan en bolsa. En lo que respecta a la naturaleza, cuanto más efectivamente se mantienen los ciclos vitales como procesos ecológicos esenciales, más invisibles se tornan. La alteración es violenta y visible; el equilibrio y la armonía se experimentan, no se ven. La invisibilidad de ambas, en el marco de la racionalidad instrumental propia del pensamiento moderno, las conduce, de facto, a una cierta reificación, en el sentido de que tanto la naturaleza como la mujer son contempladas como objetos subordinados a los intereses que, en la sociedad patriarcal, definen los hombres: explotación de los recursos, transformación del medio natural, organización de la vida en las fábricas y las empresas, acceso a los puestos directivos en la política y la administración del Estado, y adjudicación de valor a los trabajos que tienen lugar en el ámbito del hogar y a quienes los ejecutan”.

La pregunta sobre la Democracia: sus límites y posibilidades fue abordada en el décimo número. Para quienes hemos vivido largos períodos dictatoriales habiendo tenido previamente la experiencia de conocer los 
horizontes que abre y a la vez sus límites, la democracia es como el aire que respiramos: mientras lo tenemos no nos damos cuenta de su valor y de su necesidad, si nos falta hay que ver cómo nos duele. Sin embargo la democracia no es ni fácil ni placentera a veces, no es una panacea ni algo genético, es una construcción cultural que posiblemente manifiesta uno de los más altos logros de nuestra especie. Sin embargo esta construcción cultural propia de Occidente no necesariamente se traduce automáticamente en logros civilizatorios al buscar implantarla en contextos culturales que no le son propios; a veces puede funcionar y a veces no. Eso es evidente al observar la trágica situación que se vive en el Medio Oriente, donde varias sociedades fueron desestructuradas y desestabilizadas hasta un punto inimaginable al buscar imponerles nuestras nociones de la "vida buena" y nuestras concepciones políticas respecto al buen gobierno.

Gestión del cuerpo y control social fue el tema tratado en el número once. La temática del cuerpo, su expresión y exploración más allá de los cánones impuestos por la normatividad, constituyen un tema pendiente que -cuando emerge- genera des-orden, instalando la pregunta por los límites y consensos sobre nuestro orden social y cultural. Es así como las experiencias que incorporan la dimensión subjetiva del cuerpo como son el uso de drogas y la sexualidad entre otras, y que se sitúan desde lo orgiástico y festivo, son negadas, reprimidas y estigmatizadas como fuente de desorden y potencial amenaza al "contrato social”. Paralelamente se impuso en Chile un modelo de sociedad que instaló la temática del orden a través de la configuración de un discurso del control de las diferencias, el que incluye como herramientas el manejo social del temor, y el riesgo. El riesgo y el temor al otro están implícitos e introyectados en políticas sociales e imaginarios construidos por los medios de comunicación que validan el autoritarismo como un mecanismo de defensa y resolución de conflictos, al que las élites que gobiernan recurren como estrategia de respuesta ante el temor y el riesgo,develando la incapacidad de resolver las desigualdades y conflictos de convivencia que genera el actual modelo económico y social que vivimos.

El número doce llamó a reflexionar sobre el Individualismo y el Bien Común, preguntándose sobre los límites de las instituciones como el mercado, la democracia, la política y la educación, pues nuestra sociedad, la occidental ha sido, posiblemente, la que ha legado más instituciones a la cultura humana. Ello como parte de su proceso de consolidación como la forma predominante y "dominante" de estructuración de toda sociedad, impuesta a lo largo y ancho del mundo, mediante los procesos de colonización y de neocolonización actual. De ese modo, las otras formas de organización social, política y económica -surgidas en otras culturas y en sus instituciones propias-, han ido siendo reducidas a supervivencias del pasado,retazos exóticos o excentricidades históricas.

La pregunta sobre ¿Quién gobierna la política global? constituyó el eje del número catorce. pues vivimos en tiempos de crisis, turbulencias, entropías, dislocaciones, necrosis y catástrofes, en campos de la materia, la 
vida y la humanidad, en un mundo marcado por la incertidumbre instalada como una constante en nuestras vidas. Vivimos la crisis de un sistema. Los neoliberales, insisten en aplicar políticas que han devastado la naturaleza y empobrecido a los habitantes de la Tierra. El resultado es suicida. Los especialistas en medio ambiente, biosfera y ecosistemas, encuentran un silencio dramático entre los encargados de preservar el planeta. ¿Cómo encontrar, entonces, los elementos ordenadores presentes en este “caos global”? En este contexto el problema del poder se ha vuelto extremadamente complejo, desafiando nuestra capacidad de comprenderlo en todos sus aspectos.

Así sucesivamente en los números siguientes fueron planteados una gran diversidad de temas que buscaron plantear problemas imprescindibles de debatir en el ámbito público, impulsando a dar cuenta desde el trabajo académico de la multiplicidad de miradas posibles de aportar para enriquecer un necesario debate ciudadano sobre cada uno de estos temas. ellos:

A título meramente enunciativo y no exhaustivo,señalo alguno de

Hacia una cultura del agua

Buen Vivir: ¿Una auténtica alternativa post-capitalista?

Geopolítica y energía

Lo local como ámbito de contención de la globalización perversa

Migraciones Sur - Sur. Paradojas globales y promesas locales

Lo público un espacio en disputa

La Política: deliberación, técnica y movimiento

Persona y Otredad

La transgresión de las fronteras disciplinarias: la pluri, la inter y la transdisciplinariedad

El arte como comprensión de la realidad.

Identidad Latinoamericana hoy: tensiones y desafíos

Violencia: ¿partera de la historia o retorno a la sinrazón?

Ciudad: espacios y flujos

Desarrollo humano y justicia

Capitalismo tardío y sujetos transformadores

Educación como creación de nuevas relaciones posibles

Ocio e interculturalidad

Sujeto, subjetividad, identidades y sustentabilidades

Lógicas colectivas y nuevas formas de politicidad

Hacia la construcción de un nuevo paradigma social

Como es fácil de apreciar gran parte de los temas que fueron siendo tratados en estos 18 años de existencia de Polis, anticiparon gran parte de los debates que cruzan hoy a nuestras sociedades, cumpliendo así lo que fue el propósito que nos animó al iniciar su publicación:

“contribuir a la búsqueda en nuestra sociedad del interés público, de intereses generalizables y genéricos, que superen las limitaciones y rigideces propias de las miradas particulares o corporativas, las cuales siendo respetables como expresión de la diversidad de la socie- 
dad, sin embargo, no pueden pretender monopolizar la visión y la reflexión sobre temas que nos conciernen a muchos o a todos. Siendo una revista universitaria de esta sociedad que presenta crecientes tendencias a la fragmentación y la atomización, le corresponde hacerse parte de la elaboración de perspectivas de análisis, comprensión y de acción que contribuyan a su integración social y cultural. Laidea misma de universidad implica no sólo la búsqueda de conocimientos universales sino, al mismo tiempo, de enfoques y conceptualizaciones que puedan hacer que nuestra sociedad sea, en cierta medida, una para todos." 